\title{
Association between fluctuations in serum chloride levels and 30-day mortality among critically ill patients: a retrospective analysis
}

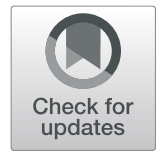

Hyo Jin Kim ${ }^{1}$, Tak Kyu Oh ${ }^{2 *}$, In-Ae Song ${ }^{2}$ and Jae Ho Lee ${ }^{3}$

\begin{abstract}
Background: This study investigated the associations of fluctuations in serum chloride $\left(\mathrm{Cl}^{-}\right)$levels with 30-day mortality after intensive care unit (ICU) admission among critically ill patients.

Methods: We retrospectively analyzed the medical records of adult patients ( $\geq 18$ years old) admitted to the ICU between January 2012 and December 2017. Positive and negative fluctuations in $\mathrm{Cl}^{-}$were defined as the differences between the $\mathrm{Cl}^{-}$upon ICU admission (baseline $\mathrm{Cl}^{-}$) and the maximum and minimum $\mathrm{Cl}^{-}$levels, respectively, measured within $72 \mathrm{~h}$ after ICU admission.

Results: The final analysis included 18,825 adult patients. In multivariable Cox regression analyses, the risk of 30-day mortality increased by $8 \%$ per 1 -mmol $\mathrm{L}^{-1}$ positive fluctuation in $\mathrm{Cl}^{-}$within $72 \mathrm{~h}$ (hazard ratio $=1.08,95 \%$ confidence interval: 1.04-1.11, $P<0.001$ ). In subgroup analyses, a positive fluctuation in $\mathrm{Cl}^{-}$was associated with increased 30-day mortality among patients with a severe positive cumulative fluid balance (FB, > 10\%), normochloremia (97-110 mmol $\mathrm{L}^{-1}$ ) or hyperchloremia (>110 mmol L ${ }^{-1}$ ) upon ICU admission. Furthermore, a negative fluctuation in the $\mathrm{Cl}^{-}$level during the first $72 \mathrm{~h}$ of an ICU stay was associated with a negative cumulative $\mathrm{FB}(<0 \%)$ or hypochloremia $(<97 \mathrm{mmol}$ $\mathrm{L}^{-1}$ ) upon ICU admission.

Conclusions: A fluctuation in the $\mathrm{Cl}^{-}$level during the first $72 \mathrm{~h}$ of an ICU stay was found to associate independently with increased 30-day mortality among critically ill adult patients. However, the nature of this association differed according to the cumulative FB status or dyschloremia status upon ICU admission.
\end{abstract}

Keywords: Intensive care unit, Mortality, Sepsis, Critical care, Hyperchloremia

\section{Background}

Serum chloride $\left(\mathrm{Cl}^{-}\right)$, the most abundant anion in plasma and interstitial fluid, is an important determinant of plasma tonicity $[1,2]$. Therefore, the maintenance of $\mathrm{Cl}^{-}$homeostasis is essential to the maintenance of electrolyte and acid-base balances in the body and the regulation of body fluids $[1,3]$.

Dyschloremia, a common complication observed in critically ill patients with varied etiologies, can be categorized as hypochloremia (i.e., a serum $\mathrm{Cl}^{-}$level below the normal range) or hyperchloremia (a serum $\mathrm{Cl}^{-}$level above the normal range) [4]. Several studies of the role

\footnotetext{
* Correspondence: airohtak@hotmail.com

${ }^{2}$ Department of Anesthesiology and Pain Medicine, Seoul National University Bundang Hospital, Gumi-ro 173 Beon-gil, Bundang-gu, Seongnam 13620, Korea

Full list of author information is available at the end of the article
}

of $\mathrm{Cl}^{-}$in critically ill patients have evaluated the association between dyschloremia and mortality in this population [4]. For example, both hyperchloremia [3, 5-7] and hypochloremia have been reported to associate with increased hospital mortality among critically ill patients [8-10]. These findings suggest that in this patient population, the association of serum $\mathrm{Cl}^{-}$levels with mortality among critically ill patients yields a U-shaped curve in which both hypo- and hyperchloremia are detrimental to patient survival [11]. Still, this issue remains controversial.

As the $\mathrm{Cl}^{-}$level is strongly affected by fluid resuscitation, previous studies of the association between dyschloremia and mortality in critically ill patients have focused on increases in $\mathrm{Cl}^{-}$loading and levels [12-15]. In critically ill patients, however, the $\mathrm{Cl}^{-}$level may decrease after intensive care unit (ICU) admission due 
to a loss of active $\mathrm{Cl}^{-}$from the gastrointestinal tract, impaired renal $\mathrm{Cl}^{-}$reabsorption, and an infusion of hypotonic fluid [1, 16]. Accordingly, overall fluctuations in $\mathrm{Cl}^{-}$levels, including positive or negative fluctuations, must be considered when determining the association of $\mathrm{Cl}^{-}$levels with mortality in critically ill patients.

Therefore, this study aimed to examine the association between both positive and negative fluctuations in $\mathrm{Cl}^{-}$ levels and 30-day mortality among critically ill patients admitted to the ICU. As the impact of fluctuations in $\mathrm{Cl}^{-}$levels after ICU admission could be affected by the cumulative fluid balance (FB) or dyschloremia upon ICU admission, we also investigated whether these factors might have different effects on the association between fluctuations in $\mathrm{Cl}^{-}$levels and 30-day mortality.

\section{Methods}

\section{Design and ethical statement}

This retrospective observational study was approved by the Institutional Review Board (IRB) of Seoul National University Bundang Hospital (IRB approval number: B-1806/474-105; approval date: 2018. 6. 11), which waived the requirement to obtain informed consent from the subjects. All data were collected by medical record technicians from the medical informatics team of the institution who were blinded to the purpose of the study.

\section{Patients}

The medical records of all adult patients aged $\geq 18$ years who were admitted to the ICU between January 2012 and December 2017 were reviewed. If a patient was admitted to the ICU two or more times during the study period, only the last admission (which may have been the most severe) was included in the analysis. Patients with incomplete or missing medical records related to $\mathrm{Cl}^{-}$levels were excluded from the analysis.

\section{Fluctuations in $\mathrm{cl}^{-}$during the 72-h period after ICU admission (main independent variable)}

In this study, the $\mathrm{Cl}^{-}$level upon ICU admission (baseline $\mathrm{Cl}^{-}$) was defined as the first $\mathrm{Cl}^{-}$level measured within $24 \mathrm{~h}$ after ICU admission. Positive and negative fluctuations in $\mathrm{Cl}^{-}$were defined as the differences between the baseline $\mathrm{Cl}^{-}$and the maximum and minimum $\mathrm{Cl}^{-}$levels, respectively, measured within $72 \mathrm{~h}$ after ICU admission. If a patient died within $72 \mathrm{~h}$ after ICU admission, the fluctuation in $\mathrm{Cl}^{-}$was calculated using data recorded in the ICU prior to death.

\section{Definitions of normo-, hypo-, and hyperchloremia on ICU admission}

We used the baseline $\mathrm{Cl}^{-}$measured as defined above to diagnose dyschloremia at the time of ICU admission. $\mathrm{Cl}^{-}$ statuses were defined as follows: normochloremia, 97-
$110 \mathrm{mmol} \mathrm{L}^{-1}$; hypochloremia, $\quad<97 \mathrm{mmol} \mathrm{L}^{-1} ; \quad$ and hyperchloremia, $>110 \mathrm{mmol} \mathrm{L}^{-1}$.

\section{Cumulative fluid balance (\%) during the 72-h period after ICU admission}

The weight-based cumulative FB (\%) was calculated using the following formula suggested in previous studies [17, 18]: (Total fluid input - output in $\mathrm{L}) \times 100 \% \times(\text { hospital admission weight in } \mathrm{kg})^{-1}$. Fluid input was defined as all types of intravenous and enteral fluids used for maintenance or resuscitation. Fluid output was defined as all types of eliminated and removed fluids (e.g., drainage, rectal, orogastric, nasogastric, and urine output). If a patient died within $72 \mathrm{~h}$ after ICU admission, the cumulative FB was calculated from ICU admission until death. All patients were subsequently categorized based on their cumulative $\mathrm{FB}$ into the following categories: positive FB ( $\geq 5 \%)$, even FB $(0-5 \%)$, or negative $\mathrm{FB}(<0 \%)$. In addition, the positive $\mathrm{FB}$ group was divided into 2 groups: mild or moderate positive FB $(5-10 \%)$ and severe FB (>10\%), based on previous definitions [19].

\section{Other measurements (potential covariates)}

The patients' physical characteristics [sex, age (years), and body mass index $\left(\mathrm{kg} \mathrm{m}^{-2}\right)$ ]; Acute Physiology and Chronic Health Evaluation II scores; comorbidities upon ICU admission [hypertension, diabetes mellitus, ischemic heart disease, cerebrovascular disease, chronic obstructive lung disease, liver disease (liver cirrhosis, hepatitis, fatty liver), dyslipidemia, chronic kidney disease, anemia, cancer]; hospital admission through the emergency department; and admitting department (internal medicine, neurologic center, post-cardiothoracic surgery, or post-other surgery) were obtained from the database. Packed red blood cell transfusion, renal replacement therapy, vasopressor infusion, and fluid administration ( $\mathrm{NaCl} 0.9 \%$, balanced crystalloid, and hydroxyethyl starch in ml) within $72 \mathrm{~h}$ after ICU admission were recorded as reflective of treatment. Additionally, the number of $\mathrm{Cl}^{-}$measurements within $72 \mathrm{~h}$ after ICU admission was also collected.

\section{0-day mortality (dependent variable)}

In this study, 30-day mortality was defined as death within 30 days of the ICU admission date. We obtained approval from the Ministry of the Interior and Safety in South Korea to determine the exact date of death of each patient, including those who were discharged from the hospital. We were able to obtain the exact dates of death for all patients as of May 16, 2018. 
Aim

This study assessed associations of fluctuations (positive or negative) in the $\mathrm{Cl}^{-}$levels within $72 \mathrm{~h}$ after ICU admission with 30-day mortality after ICU admission. Additionally, we investigated whether this association might differ according to the cumulative FB status or dyschloremia status upon ICU admission.

\section{Statistical analysis}

Initially, the relationship between a positive or negative fluctuation in $\mathrm{Cl}^{-}$levels within $72 \mathrm{~h}$ after ICU admission (continuous variable) and 30-day mortality was first examined using a restricted cubic spline (Additional file 3: Figure S1 and Additional file 4: Figure S2, respectively). Next, we subdivided both positive and negative fluctuations in $\mathrm{Cl}^{-}$into two groups each, using a cut-off point of $10 \mathrm{mmol} \mathrm{L}^{-1}$. First, as the end points of the U-shaped curve of 30-day mortality associated with both positive and negative fluctuations in $\mathrm{Cl}^{-}$occurred at approximately $10 \mathrm{mmol} \mathrm{L}^{-1}$ in the cubic spline analyses, this stratification could maximize the impact of fluctuations in $\mathrm{Cl}^{-}$on 30-day mortality. Second, a previous similar study suggested that 30-day mortality was lowest among critically ill patients with systemic inflammatory response syndrome who exhibited a $0-10 \mathrm{mmol} \mathrm{L}^{-1}$ increase in $\mathrm{Cl}^{-}$[5].

We next examined the independent associations of each of the covariates with 30-day mortality using a univariable Cox regression analysis (Additional file 1: Table S1). Covariates that received a $P<0.1$ in the univariable analysis were included in the final multivariable Cox regression analysis for covariate adjustment. The main independent variable, fluctuation in $\mathrm{Cl}^{-}$, was included as both a continuous and categorical variable $(>10 \mathrm{mmol}$ $\mathrm{L}^{-1}$ or $\leq 10 \mathrm{mmol} \mathrm{L}^{-1}$ ) in different models to avoid multicollinearity between variables. Then, we investigated the interactions of cumulative FB groups or dyschloremia upon ICU admission with the effects of fluctuations in $\mathrm{Cl}^{-}$on 30-day mortality. After confirming these interactions, we performed a subgroup analysis according to the previously described cumulative FB groups and dyschloremia upon ICU admission using the Bonferroni correction to reduce type 1 errors in multiple comparisons [20]. The results of the Cox regression analysis are presented as hazard ratios (HRs) with 95\% confidence intervals (CIs), and a log-minus-log plot was used to confirm that the central assumptions of the Cox proportional hazard model were satisfied in each multivariable model.

All data were analyzed using IBM SPSS version 24.0 (IBM, Armonk, NY, USA). A $P<0.05$ was considered statistically significant. In the subgroup analyses, a $P<0.012$ or $<0.017$ was considered statistically significant in the analyses conducted according to FB groups or dyschloremia upon ICU admission, respectively, after applying the Bonferroni correction.

\section{Results}

A total of 40,533 ICU admissions were recorded between January 2012 and December 2017. Of these, 10,135 cases involving patients with more than two admissions were excluded. Among the 30,398 admissions consequently included in the initial screening, 5440 involving patients younger than 18 years and 6133 with incomplete or missing medical records relevant to this analysis were excluded. The final analysis sample included 18,825 adult patients, among whom 1011 (5.1\%) died within 30 days (Fig. 1). The baseline characteristics of all patients included in the analysis are shown in Table 1.

\section{Fluctuations in $\mathrm{Cl}^{-}$levels within $72 \mathrm{~h}$ after ICU admission and 30-day mortality}

The results of the univariable and multivariable Cox regression analyses are presented in Additional file 1: Table S1. The multivariable Cox regression analysis (Table 2) revealed that each $1-\mathrm{mmol} \mathrm{L}^{-1}$ positive fluctuation in the $\mathrm{Cl}^{-}$level was associated with an $8 \%$ increase in the risk of 30 -day mortality $(\mathrm{HR}=1.08,95 \% \mathrm{CI}$ : $1.04-$ $1.11, P<0.001$; model 1 ). When patients exhibiting positive fluctuations were stratified using a cut-off value of a $10-\mathrm{mmol} \mathrm{L}^{-1}$ positive fluctuation in $\mathrm{Cl}^{-}$levels within $72 \mathrm{~h}$ of ICU admission, those with fluctuations above this value (> 10 group) had a 3.37-fold higher risk of 30-day mortality, compared to those with fluctuations below this value ( $\leq 10$ group $)(\mathrm{HR}=3.37,95 \% \mathrm{CI}: 2.01-5.67, P<0.001$; model 2). However, a negative fluctuation in $\mathrm{Cl}^{-}$was not associated significantly with the risk of 30-day mortality $(P=0.313$ in model 1 and $P=0.883$ in model 2$)$.

\section{Subgroup analysis according to cumulative fluid balance and dyschloremia on ICU admission}

As the interactions of FB groups and dyschloremia upon ICU admission with fluctuations in $\mathrm{Cl}^{-}$affected 30-day mortality (Additional file 2: Table S2), we performed subgroup analyses (Table 3). Among patients in the negative $\mathrm{FB}$ group (<0\%), a $>10-\mathrm{mmol} \mathrm{L}^{-1}$ negative fluctuation in $\mathrm{Cl}^{-}$was associated with a 3.04-fold increase in 30-day mortality, compared to those with a negative fluctuation of $\leq 10 \mathrm{mmol} \mathrm{L}^{-1} \quad(\mathrm{HR}=3.04,95 \%$ CI: $1.32-7.03, P=0.009)$. Among patients in the severely positive $\mathrm{FB}$ group (>10\%), a $>10 \mathrm{mmol} \mathrm{L}^{-1}$ negative fluctuation in $\mathrm{Cl}^{-}$was associated with a 2.07 -fold increase in 30-day mortality, compared to those with a negative fluctuation of $\leq 10 \mathrm{mmol} \mathrm{L}^{-1} \quad(\mathrm{HR}=2.07,95 \%$ CI: $1.35-3.16, P=0.001)$.

In addition, a $>10 \mathrm{mmol} \mathrm{L}{ }^{-1}$ positive fluctuation in $\mathrm{Cl}^{-}$ was associated with 2.59 -fold $(\mathrm{HR}=2.59$, 95\% CI: 1.74 


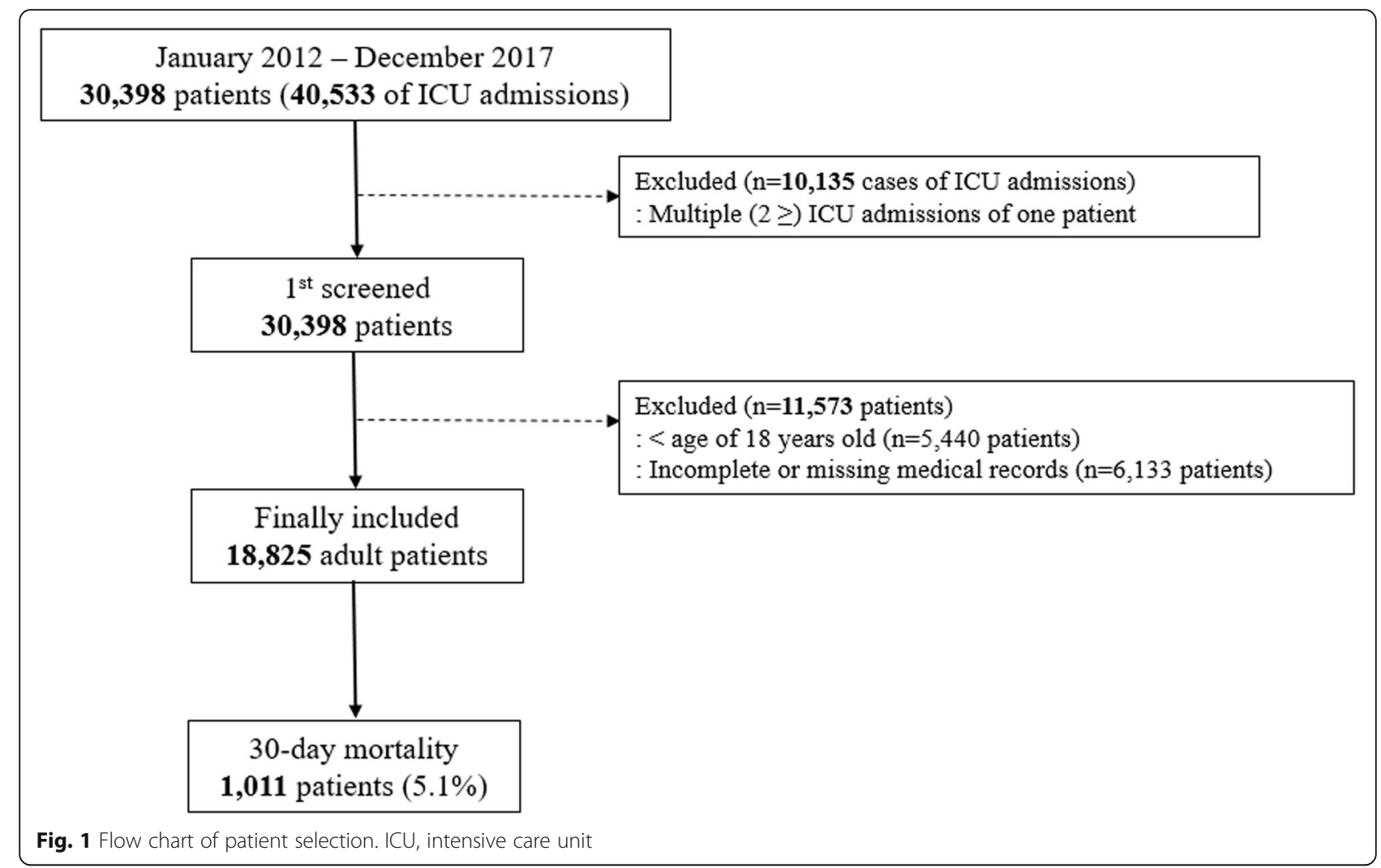

3.86, $P<0.001)$ and 1.75 -fold increases $(\mathrm{HR}=1.75,95 \%$ CI: $1.11-2.74, P=0.014)$ in 30 -day mortality among patients with normochloremia and hyperchloremia upon ICU admission, respectively. On the other hand, a $>10$ mmol L${ }^{-1}$ negative fluctuation in $\mathrm{Cl}^{-}$was associated with a 4.66-fold increase in 30-day mortality (HR-4.66, 95\% CI: $1.39-15.65, P=0.012)$ among patients with hypochloremia upon ICU admission.

Figure $2 \mathrm{a}$ and $\mathrm{b}$ depict the restricted cubic splines for 30-day mortality with positive and negative fluctuations in $\mathrm{Cl}^{-}$, respectively, according to cumulative $\mathrm{FB}$ groups. Figure $3 \mathrm{a}$ and $\mathrm{b}$ depict the restricted cubic splines for 30-day mortality with positive and negative fluctuations in $\mathrm{Cl}^{-}$, respectively, according to the dyschloremia status upon ICU admission.

\section{Discussion}

Our findings from a retrospective sample of ICU patients generally suggest that a positive fluctuation in $\mathrm{Cl}^{-}$ levels within $72 \mathrm{~h}$ after ICU admission is associated with a greater risk of 30-day mortality. By contrast, no similar association was observed with a negative fluctuation in $\mathrm{Cl}^{-}$levels. However, this association might differ according to the cumulative FB status or dyschloremia status upon ICU admission. In these subgroup analyses, a positive fluctuation in $\mathrm{Cl}^{-}$was associated with an increased risk of 30-day mortality among patients in the severe positive FB group (>10\%) and those with normochloremia or hyperchloremia upon ICU admission, whereas a negative fluctuation in $\mathrm{Cl}^{-}$was associated with an increased risk of 30-day mortality among patients with a negative FB $(<0 \%)$ or hypochloremia upon ICU admission. These findings are valuable because we evaluated the effects of both positive and negative fluctuations in $\mathrm{Cl}^{-}$on post-ICU admission mortality after considering the interactions of the cumulative FB and dyschloremia status upon ICU admission. Our results further suggest that in the ICU, more severely ill patients are at an increased risk of dysregulated $\mathrm{Cl}^{-}$handling because they are highly likely to receive more interventions and larger amounts of crystalloid and to experience altered fluid handling.

First, the observation that a positive fluctuation in $\mathrm{Cl}^{-}$ might be a risk factor for mortality among patients with severe positive $\mathrm{FB}(>10 \%)$ is our most interesting finding. This result is consistent with the findings of a similar previous study that reported an association of an increase in the $\mathrm{Cl}^{-}$load with mortality among patients receiving large-volume resuscitation [21]. These results suggest that the $\mathrm{Cl}^{-}$load may have a significant impact in patients receiving large-volume fluid resuscitation. Second, we demonstrated no association of a positive fluctuation in $\mathrm{Cl}^{-}$with 30-day mortality among patients with hypochloremia upon ICU admission. By contrast, a 
Table 1 Baseline characteristics of adults patients admitted to the ICU during 2012-2017

\begin{tabular}{|c|c|c|c|}
\hline Variable & Total $(18,825)$ & Mean & SD \\
\hline Sex: male & $10,839(57.6 \%)$ & & \\
\hline Age, years & & 63.7 & 16.0 \\
\hline Body mass index, $\mathrm{kg} \mathrm{m}^{-2}$ & & 23.6 & 3.9 \\
\hline APACHE ॥ & & 20.3 & 9.8 \\
\hline
\end{tabular}

Comorbidities at ICU admission

\begin{tabular}{|c|c|}
\hline Hypertension & $8160(43.3 \%)$ \\
\hline Diabetes mellitus & $1673(8.9 \%)$ \\
\hline Ischemic heart disease & $447(2.4 \%)$ \\
\hline Cerebrovascular disease & $856(4.5 \%)$ \\
\hline Chronic obstructive lung disease & $836(4.4 \%)$ \\
\hline Liver disease (LC, hepatitis, fatty liver) & $603(3.2 \%)$ \\
\hline Dyslipidemia & $1191(6.3 \%)$ \\
\hline Chronic kidney disease & $3236(17.2 \%)$ \\
\hline Anemia $\left(\mathrm{Hb}<10 \mathrm{~g} \mathrm{dl}^{-1}\right)$ & $6919(36.8 \%)$ \\
\hline Cancer & $4001(21.3 \%)$ \\
\hline \multicolumn{2}{|l|}{ haracteristics of ICU admission } \\
\hline Admission through emergency department & $10,950(58.2 \%$ \\
\hline \multicolumn{2}{|l|}{ Admitting department } \\
\hline Internal medicine & $3851(20.5 \%)$ \\
\hline Neurologic center & $4770(25.3 \%)$ \\
\hline Post-cardiothoracic surgery & $5765(30.6 \%)$ \\
\hline Post-other surgery & $4438(23.6 \%)$ \\
\hline \multicolumn{2}{|l|}{ Length of ICU stay, day } \\
\hline \multicolumn{2}{|l|}{ Length of hospital stay, day } \\
\hline pRBC transfusion within $72 \mathrm{~h}$ after ICU adm & $8294(44.1 \%)$ \\
\hline RRT within $72 \mathrm{~h}$ after ICU adm & $458(2.4 \%)$ \\
\hline Vasopressor infusion within $72 \mathrm{~h}$ after ICU adm & $3433(18.2 \%)$ \\
\hline \multicolumn{2}{|l|}{${ }^{a}$ Cumulative fluid balance within $72 \mathrm{~h}$ after ICU adm } \\
\hline Negative $(<0 \%)$ & $3933(20.9 \%)$ \\
\hline Even $(0-5 \%)$ & $9680(51.4 \%)$ \\
\hline Positive, Mild to moderate (5-10\%) & $3889(20.7 \%)$ \\
\hline Positive, Severe (> 10\%) & 1323 (7.0\%) \\
\hline
\end{tabular}

Fluid administration for $72 \mathrm{~h}$ after ICU admission

$\mathrm{NaCl} 0.9 \%, \mathrm{ml}$

Balanced crystalloid, $\mathrm{ml}$

Hydroxyethyl starch, $\mathrm{ml}$

Serum chloride $\left(\mathrm{Cl}^{-}\right)$in $\mathrm{ICU}, \mathrm{mmol} \mathrm{\textrm {L } ^ { - 1 }}$

The number of measurements for $72 \mathrm{~h}$ after ICU adm

$\mathrm{Cl}^{-}$on ICU admission (baseline $\mathrm{Cl}^{-}$)

Normochloremia on ICU adm (97-110 $\mathrm{mmol} \mathrm{L}^{-1}$ )

$11,861(63.0 \%)$

Hypochloremia on ICU adm ( $\left.<97 \mathrm{mmol} \mathrm{L}^{-1}\right)$

$1753(9.3 \%)$

Hyperchloremia on ICU adm (> $\left.110 \mathrm{mmol} \mathrm{L}^{-1}\right)$

$5211(27.7 \%)$ 
Table 1 Baseline characteristics of adults patients admitted to the ICU during 2012-2017 (Continued)

\begin{tabular}{|c|c|c|c|}
\hline Variable & Total $(18,825)$ & Mean & SD \\
\hline${ }^{\mathrm{b}}$ Positive fluctuation of $\mathrm{Cl}^{-}$for $72 \mathrm{~h}$ after ICU adm & & 4.1 & 4.1 \\
\hline$>10 \mathrm{mmol} \mathrm{L}^{-1}$ & $1243(6.6 \%)$ & & \\
\hline${ }^{\mathrm{c}}$ Negative fluctuation of $\mathrm{Cl}^{-}$for $72 \mathrm{~h}$ after ICU adm & & 2.9 & 3.5 \\
\hline$>10 \mathrm{mmol} \mathrm{L}^{-1}$ & $682(3.6 \%)$ & & \\
\hline 30-day mortality after ICU admission & $1011(5.1 \%)$ & & \\
\hline
\end{tabular}

previous study by $\mathrm{Oh}$ and colleagues reported that an increase in the $\mathrm{Cl}^{-}$level was associated with a decrease of mortality among hypochloremic patients with sepsis or septic shock [22]. Our study and the study by Oh and colleagues differed with respect to focus. Specifically, we focused on a mixed ICU population, whereas $\mathrm{Oh}$ and colleagues analyzed only patients with sepsis or septic shock who might have tended to present with more severe conditions. This difference in patient populations might have caused the discrepancy in the impact of positive fluctuations in $\mathrm{Cl}^{-}$on mortality among critically ill patients. Future studies are needed to confirm the impact of the $\mathrm{Cl}^{-}$load on mortality in patients with hypochloremia.
Our findings regarding the effects of a negative fluctuation in $\mathrm{Cl}^{-}$are novel and interesting, as no previous study had evaluated the impact of a decreased $\mathrm{Cl}^{-}$level after ICU admission on mortality. We found that a negative fluctuation in $\mathrm{Cl}^{-}$might be a risk factor for 30-day mortality in patients with a negative $\mathrm{FB}(<5 \%)$ or hypochloremia upon ICU admission. Consistent with previous studies, hypochloremia upon ICU admission was identified as an independent risk factor for mortality [23, 24]. Among patients in the cumulative negative $\mathrm{FB}$ group $(<0 \%)$, a negative fluctuation in $\mathrm{Cl}^{-}$within $72 \mathrm{~h}$ after ICU admission suggested a significant body fluid loss without proper fluid replacement, which may have been consequent to septic shock, massive bleeding, or gastrointestinal losses.

Table 2 Multivariable Cox regression analysis of 30-day mortality after ICU admission according to positive and negative fluctuations in $\mathrm{Cl}^{-}$levels within $72 \mathrm{~h}$ after ICU admission

\begin{tabular}{|c|c|c|}
\hline \multirow[t]{2}{*}{ Variables } & Multivariable model & $P$ \\
\hline & \multicolumn{2}{|l|}{ Hazard ratio $(95 \% \mathrm{Cl})$} \\
\hline \multicolumn{3}{|l|}{ Model 1} \\
\hline${ }^{\text {a}}$ Positive fluctuation in $\mathrm{Cl}^{-}\left(1 \mathrm{mmol} \mathrm{L}{ }^{-1}\right.$ increase $)$ & $1.08(1.04,1.11)$ & $<0.001$ \\
\hline${ }^{b}$ Negative fluctuation in $\mathrm{Cl}^{-}\left(1 \mathrm{mmol} \mathrm{\textrm {L } ^ { - 1 }}\right.$ increase $)$ & $1.03(0.98,1.08)$ & 0.313 \\
\hline \multicolumn{3}{|l|}{ Cumulative FB group ${ }^{c}$} \\
\hline Even $(0-5 \%)$ & 1 & $(<0.001)$ \\
\hline Negative $(<0 \%)$ & $0.97(0.72,1.32)$ & 0.868 \\
\hline Positive, Mild to moderate (5-10\%) & $2.01(1.57,2.57)$ & $<0.001$ \\
\hline Positive, Severe (> 10\%) & $4.06(3.10,5.32)$ & $<0.001$ \\
\hline \multicolumn{3}{|l|}{ Dyschloremia at ICU admission } \\
\hline Normochloremia (97-110 mmol L ${ }^{-1}$ ) & 1 & $(<0.001)$ \\
\hline Hypochloremia (<97 mmol L-1) & $1.99(1.57,2.51)$ & $<0.001$ \\
\hline Hyperchloremia (> $110 \mathrm{mmol} \mathrm{L}^{-1}$ ) & $0.78(0.60,1.00)$ & 0.054 \\
\hline \multicolumn{3}{|l|}{ Model 2} \\
\hline${ }^{\text {aP }}$ ositive fluctuation of $\mathrm{Cl}^{-}>10 \mathrm{mmol} \mathrm{L}^{-1}$ & $3.37(2.01,5.67)$ & $<0.001$ \\
\hline${ }^{\mathrm{b}}$ Negative fluctuation of $\mathrm{Cl}^{-}>10 \mathrm{mmol} \mathrm{L}^{-1}$ & $0.94(0.38,2.30)$ & 0.883 \\
\hline
\end{tabular}

ICU intensive care unit, FB fluid balance

${ }^{\text {a }}$ Positive fluctuation in $\mathrm{Cl}^{-}$: (Maximum $\mathrm{Cl}^{-}$- Preadmission $\mathrm{Cl}^{-}$) for $72 \mathrm{~h}$ after $\mathrm{ICU}$ admission

${ }^{\text {b}}$ Negative fluctuation in $\mathrm{Cl}^{-}$: (Preadmission $\mathrm{Cl}^{-}-$Minimum $\mathrm{Cl}^{-}$) for $72 \mathrm{~h}$ after ICU admission

${ }^{c}$ Cumulative fluid balance (\%): (Total input fluid - total output fluid, L) $\times 100 \times$ weight at admission $(\mathrm{kg})^{-1}$ 
Table 3 Subgroup analysis according to the cumulative fluid balance group within $72 \mathrm{~h}$ after ICU admission and dyschloremia upon ICU admission

\begin{tabular}{|c|c|c|}
\hline \multirow[t]{2}{*}{ Variables } & \multicolumn{2}{|l|}{ Multivariable model } \\
\hline & Hazard Ratio (95\% Cl) & $P^{*}$ \\
\hline \multicolumn{3}{|l|}{${ }^{a}$ Cumulative FB group (subgroup analysis 1) } \\
\hline \multicolumn{3}{|l|}{ Even (0-5\%): 9680} \\
\hline${ }^{b}$ Positive fluctuation of $\mathrm{Cl}^{-}>10 \mathrm{mmol} \mathrm{L}^{-1}$ & $1.76(1.12,2.78)$ & 0.015 \\
\hline${ }^{c}$ Negative fluctuation of $\mathrm{Cl}^{-}>10 \mathrm{mmol} \mathrm{L}^{-1}$ & $1.01(0.46,2.21)$ & 0.986 \\
\hline \multicolumn{3}{|l|}{ Negative (<0\%): 3933} \\
\hline 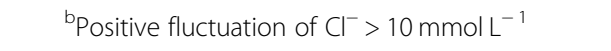 & $1.34(0.64,2.83)$ & 0.441 \\
\hline${ }^{c}$ Negative fluctuation of $\mathrm{Cl}^{-}>10 \mathrm{mmol} \mathrm{L}^{-1}$ & $\mathbf{3 . 0 4}(1.32,7.03)$ & 0.009 \\
\hline \multicolumn{3}{|l|}{ Positive, Mild to moderate (5-10\%): 3889} \\
\hline${ }^{b}$ Positive fluctuation of $\mathrm{Cl}^{-}>10 \mathrm{mmol} \mathrm{L}^{-1}$ & $1.31(0.79,2.17)$ & 0.289 \\
\hline${ }^{c}$ Negative fluctuation of $\mathrm{Cl}^{-}>10 \mathrm{mmol} \mathrm{L}^{-1}$ & $1.02(0.50,2.05)$ & 0.967 \\
\hline \multicolumn{3}{|l|}{ Positive, Severe (> 10\%): 1323} \\
\hline${ }^{\mathrm{b}}$ Positive fluctuation of $\mathrm{Cl}^{-}>10 \mathrm{mmol} \mathrm{\textrm {L } ^ { - 1 }}$ & $2.07(1.35,3.16)$ & 0.001 \\
\hline${ }^{c}$ Negative fluctuation of $\mathrm{Cl}^{-}>10 \mathrm{mmol} \mathrm{L}^{-1}$ & $1.30(0.80,2.11)$ & 0.287 \\
\hline Dyschloremia on ICU admission (subgroup analysis 2) & & $P^{* *}$ \\
\hline \multicolumn{3}{|l|}{ Normochloremia (97-110 mmol L-1): 11,861 } \\
\hline 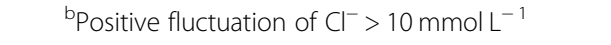 & $2.59(1.74,3.86)$ & $<0.001$ \\
\hline${ }^{c}$ Negative fluctuation of $\mathrm{Cl}^{-}>10 \mathrm{mmol} \mathrm{L}^{-1}$ & $1.00(0.61,1.66)$ & 0.993 \\
\hline \multicolumn{3}{|l|}{ Hypochloremia (<97 mmol L-1): 1753} \\
\hline${ }^{b}$ Positive fluctuation of $\mathrm{Cl}^{-}>10 \mathrm{mmol} \mathrm{L}^{-1}$ & $1.03(0.69,1.53)$ & 0.903 \\
\hline${ }^{c}$ Negative fluctuation of $\mathrm{Cl}^{-}>10 \mathrm{mmol} \mathrm{L}^{-1}$ & $4.66(1.39,15.65)$ & 0.012 \\
\hline \multicolumn{3}{|l|}{ Hyperchloremia (> $110 \mathrm{mmol} \mathrm{L}^{-1}$ ): 5211} \\
\hline${ }^{b}$ Positive fluctuation of $\mathrm{Cl}^{-}>10 \mathrm{mmol} \mathrm{L}^{-1}$ & $\mathbf{1 . 7 5}(1.11,2.74)$ & 0.014 \\
\hline${ }^{c}$ Negative fluctuation of $\mathrm{Cl}^{-}>10 \mathrm{mmol} \mathrm{L}^{-1}$ & $1.50(0.93,2.40)$ & 0.095 \\
\hline
\end{tabular}

A $P^{*}<0.012$ and $P^{* *}<0.017$ indicate statistical significance after Bonferroni correction in analyses of four subgroups

$I C U$ intensive care unit, $F B$ fluid balance

${ }^{a}$ Cumulative fluid balance (\%): (Total input fluid - total output fluid, L) $\times 100 \times$ weight at admission $(\mathrm{kg})^{-1}$

${ }^{b}$ Positive fluctuation in $\mathrm{Cl}^{-}$: (Maximum $\mathrm{Cl}^{-}$- Preadmission $\mathrm{Cl}^{-}$) for $72 \mathrm{~h}$ after ICU admission.

${ }^{c}$ Negative fluctuation in $\mathrm{Cl}^{-}$: (Preadmission $\mathrm{Cl}^{-}-$Minimum $\mathrm{Cl}^{-}$) for $72 \mathrm{~h}$ after ICU admission.

Likewise, patients with hypochloremia upon ICU admission and a negative fluctuation in $\mathrm{Cl}^{-}$within the subsequent $72-\mathrm{h}$ period might have experienced insufficient fluid resuscitation. However, the information regarding this issue remains lacking, and further study is needed to confirm the relationship between a negative fluctuation in $\mathrm{Cl}^{-}$and the outcomes of critically ill patients.

Another interesting point of note in this study is the establishment of a cut-off point of $10 \mathrm{mmol} \mathrm{L}^{-1}$ for fluctuations in the $\mathrm{Cl}^{-}$level within $72 \mathrm{~h}$ after ICU admission. This value may be used as a reference in studies of 30-day mortality after ICU admission. Neyra and colleagues reported that a $5-\mathrm{mmol} \mathrm{L}^{-1}$ increase in the $\mathrm{Cl}^{-}$level at $72 \mathrm{~h}$ after ICU admission was associated with a 1.37-fold increase in hospital mortality [3], while Shaw and colleagues reported that a cut-off of $10 \mathrm{mmol} \mathrm{L}^{-1}$ (identical to our study cut-off value) was associated with increased hospital mortality in patients with systemic inflammatory response syndrome [3, 5]. Our study differed from those previous studies because our analysis included all general critically ill patients (including post-surgical patients) and demonstrated associations between dyschloremia and 30-day mortality using both positive and negative fluctuations in $\mathrm{Cl}^{-}$levels, respectively. From a statistical perspective, the optimal cut-off points for continuous variables could be determined using a cubic spline approach to maximize the impact on outcomes [25]. Therefore, we used $10 \mathrm{mmol} \mathrm{L}^{-1}$ as a cut-off point because this was very near the endpoints of the U-shaped curves of 30-day mortality in our cubic spline analyses (Additional file 3: Figure $\mathrm{S} 1$ and Additional file 4: Figure S2).

This study had several limitations of note. First, it may have been subject to the selection bias characteristic of a retrospective cohort design. To minimize this bias, however, data collection and handling were performed by 

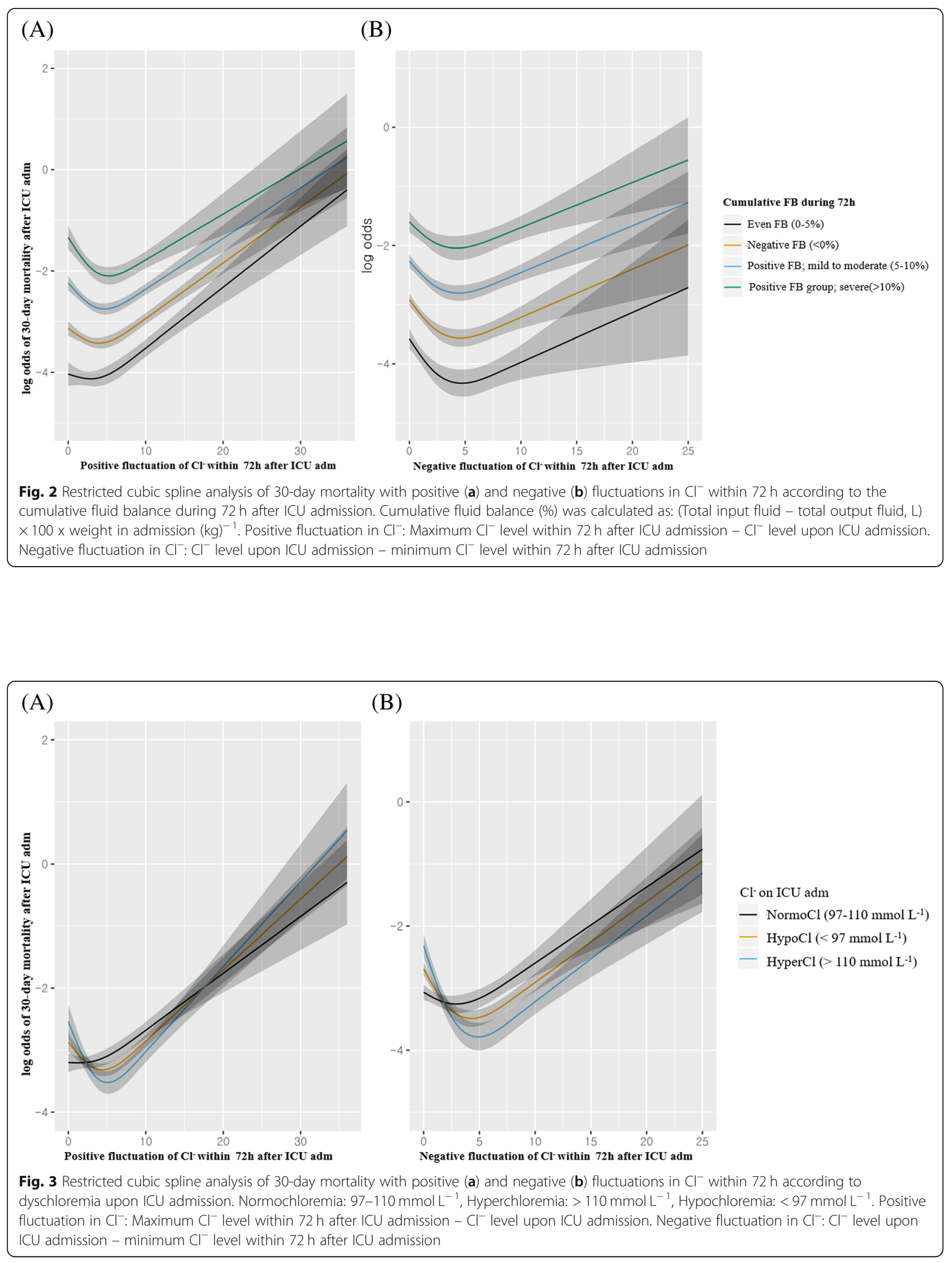
medical record technicians blinded to the purpose of the study. Second, the generalizability of our results may be limited by the single-center nature of the population and setting. Third, although we included the number of measurements within $72 \mathrm{~h}$ after ICU admission to reduce bias, our study was limited by the fact that the patients' $\mathrm{Cl}^{-}$ levels were not measured at the same time point via the same method. Overall, a multicenter prospective study should be performed in future to confirm our findings.

\section{Conclusions}

This study has demonstrated that a positive fluctuation in the $\mathrm{Cl}^{-}$levels within the first $72 \mathrm{~h}$ of an ICU stay is associated with increased 30-day mortality among critically ill patients with a severe positive cumulative FB (>10\%), normochloremia, or hyperchloremia at the time of ICU admission. Additionally, a negative fluctuation in the $\mathrm{Cl}^{-}$level during the first $72 \mathrm{~h}$ of an ICU stay was associated with increased 30-day mortality among critically ill patients with a negative cumulative FB $(<0 \%)$ or hypochloremia upon ICU admission.

\section{Additional files}

\section{Additional file 1: Table S1. Univariable Cox regression analysis of} covariates for 30-day mortality after ICU admission. (DOCX 19 kb)

Additional file 2: Table S2. Interactions between fluctuations in $\mathrm{Cl}$ levels with the associations of cumulative FB and dyschloremia upon ICU admission with 30-day mortality in a multivariable Cox regression analysis. (DOCX $18 \mathrm{~kb}$ )

Additional file 3: Figure S1. Restricted cubic spline analysis between 30-day mortality and a positive fluctuation in $\mathrm{Cl}^{-}$within $72 \mathrm{~h}$. (TIF $35 \mathrm{~kb}$ )

Additional file 4: Figure S2. Restricted cubic spline analysis between 30-day mortality and a negative fluctuation in $\mathrm{Cl}^{-}$within $72 \mathrm{~h}$. (TIF $38 \mathrm{~kb}$ )

\section{Abbreviations}

Cl: Serum chloride; ICU: Intensive care unit; FB: Fluid balance; IRB: Institutional review board; HR: Hazard ratio; $\mathrm{Cl}$ : Confidence interval

\section{Acknowledgements}

None

\section{Funding}

This research did not receive any specific grant from funding agencies in the public, commercial, or not-for-profit sectors.

\section{Availability of data and materials}

The datasets generated and analyzed during the current study are available from the corresponding author on reasonable request.

\section{Authors' contributions}

TKO and H.J.K contributed to the study design, analyzed the data, and drafted the first manuscript. IAS and JHL contributed to the data acquisition and critically revised the manuscript. All authors read and approved the final version of the manuscript.

\section{Ethics approval and consent to participate}

This retrospective observational study was approved by the Institutional Review Board (IRB) of Seoul National University Bundang Hospital (IRB approval number: B-1806/474-105; approval date: 2018. 6. 11), which waived the requirement to obtain informed consent from the subjects.
Consent for publication

Not applicable.

\section{Competing interests}

The authors declare that they have no competing interests.

\section{Publisher's Note}

Springer Nature remains neutral with regard to jurisdictional claims in published maps and institutional affiliations.

\section{Author details}

${ }^{1}$ Department of Anesthesiology and Pain Medicine, Inje University Seoul Paik hospital, Seoul, South Korea. ${ }^{2}$ Department of Anesthesiology and Pain Medicine, Seoul National University Bundang Hospital, Gumi-ro 173 Beon-gil, Bundang-gu, Seongnam 13620, Korea. ${ }^{3}$ Division of Pulmonary and Critical Care Medicine, Department of Internal Medicine, Seoul National University Bundang Hospital, Seongnam, South Korea.

Received: 8 April 2019 Accepted: 9 May 2019

Published online: 17 May 2019

\section{References}

1. Berend K, van Hulsteijn LH, Gans RO. Chloride: the queen of electrolytes? Eur J Intern Med. 2012;23(3):203-11.

2. Wolfe LA, Kemp JG, Heenan AP, Preston RJ, Ohtake PJ. Acid-base regulation and control of ventilation in human pregnancy. Can J Physiol Pharmacol. 1998;76(9):815-27.

3. Neyra JA, Canepa-Escaro F, Li X, Manllo J, Adams-Huet B, Yee J, Yessayan L, Acute kidney injury in critical illness study G. Association of Hyperchloremia with Hospital Mortality in critically ill septic patients. Crit Care Med. 2015; 43(9):1938-44

4. Pfortmueller CA, Uehlinger D, von Haehling S, Schefold JC. Serum chloride levels in critical illness-the hidden story. Intensive Care Med Exp. 2018;6(1):10

5. Shaw AD, Raghunathan K, Peyerl FW, Munson SH, Paluszkiewicz SM, Schermer CR. Association between intravenous chloride load during resuscitation and in-hospital mortality among patients with SIRS. Intensive Care Med. 2014:40(12):1897-905.

6. Shaw AD, Schermer CR, Lobo DN, Munson SH, Khangulov V, Hayashida DK, Kellum JA. Impact of intravenous fluid composition on outcomes in patients with systemic inflammatory response syndrome. Crit Care. 2015;19:334.

7. Boniatti MM, Cardoso PR, Castilho RK, Vieira SR. Is hyperchloremia associated with mortality in critically ill patients? A prospective cohort study. J Crit Care. 2011;26(2):175-9.

8. De Bacquer D, De Backer G, De Buyzere M, Kornitzer M. Is low serum chloride level a risk factor for cardiovascular mortality? J Cardiovasc Risk. 1998;5(3):177-84.

9. Grodin JL, Simon J, Hachamovitch R, Wu Y, Jackson G, Halkar M, Starling RC, Testani JM, Tang WH. Prognostic role of serum chloride levels in acute decompensated heart failure. J Am Coll Cardiol. 2015;66(6):659-66.

10. Grodin $\mathrm{L}$, Verbrugge FH, Ellis SG, Mullens W, Testani JM, Tang WH. Importance of abnormal chloride homeostasis in stable chronic heart failure. Circ Heart Fail. 2016;9(1):e002453.

11. Soussi S, Ferry A, Chaussard M, Legrand M. Chloride toxicity in critically ill patients: What's the evidence? Anaesth Crit Care Pain Med. 2017;36(2):125-30.

12. Asfar P, Schortgen F, Boisrame-Helms J, Charpentier J, Guerot E, Megarbane B, Grimaldi D, Grelon F, Anguel N, Lasocki S, et al. Hyperoxia and hypertonic saline in patients with septic shock (HYPERS2S): a two-by-two factorial, multicentre, randomised, clinical trial. Lancet Respir Med. 2017;5(3):180-90.

13. Kawano-Dourado L, Zampieri FG, Azevedo LCP, Correa TD, Figueiro M, Semler MW, Kellum JA, Cavalcanti AB. Low- versus high-chloride content intravenous solutions for critically ill and perioperative adult patients: a systematic review and meta-analysis. Anesth Analg. 2018;126(2):513-21.

14. Krajewski ML, Raghunathan K, Paluszkiewicz SM, Schermer CR, Shaw AD Meta-analysis of high- versus low-chloride content in perioperative and critical care fluid resuscitation. Br J Surg. 2015;102(1):24-36.

15. Raghunathan K, Murray PT, Beattie WS, Lobo DN, Myburgh J, Sladen R, Kellum JA, Mythen MG, Shaw AD, Group AXI. Choice of fluid in acute illness: what should be given? An international consensus. Br J Anaesth. 2014; 113(5):772-83.

16. Yunos NM, Bellomo R, Story D, Kellum J. Bench-to-bedside review: chloride in critical illness. Crit Care. 2010;14(4):226. 
17. Balakumar V, Murugan R, Sileanu FE, Palevsky P, Clermont G, Kellum JA. Both positive and negative fluid balance may be associated with reduced long-term survival in the critically ill. Crit Care Med. 2017;45(8):e749-57.

18. Selewski DT, Cornell TT, Lombel RM, Blatt NB, Han YY, Mottes T,

Kommareddi M, Kershaw DB, Shanley TP, Heung M. Weight-based determination of fluid overload status and mortality in pediatric intensive care unit patients requiring continuous renal replacement therapy. Intensive Care Med. 2011;37(7):1166-73.

19. O'Connor ME, Prowle JR. Fluid Overload. Crit Care Clin. 2015;31(4):803-21.

20. Shi Q, Pavey ES, Carter RE. Bonferroni-based correction factor for multiple, correlated endpoints. Pharm Stat. 2012;11(4):300-9.

21. Sen A, Keener CM, Sileanu FE, Foldes E, Clermont G, Murugan R, Kellum JA. Chloride content of fluids used for large-volume resuscitation is associated with reduced survival. Crit Care Med. 2017;45(2):e146-53.

22. Oh HJ, Kim SJ, Kim YC, Kim EJ, Jung IY, Oh DH, Jeong SJ, Ku NS, Han SH, Choi JY, et al. An increased chloride level in hypochloremia is associated with decreased mortality in patients with severe sepsis or septic shock. Sci Rep. 2017;7(1):15883.

23. Tani M, Morimatsu H, Takatsu F, Morita K. The incidence and prognostic value of hypochloremia in critically ill patients. ScientificWorldJournal. 2012; 2012:474185.

24. Kimura S, Matsumoto S, Muto N, Yamanoi T, Higashi T, Nakamura K, Miyazaki M, Egi M. Association of serum chloride concentration with outcomes in postoperative critically ill patients: a retrospective observational study. J Intensive Care. 2014;2(1):39.

25. Altman DG, Lausen B, Sauerbrei W, Schumacher M. Dangers of using "optimal" cutpoints in the evaluation of prognostic factors. J Natl Cancer Inst. 1994;86(11):829-35.

Ready to submit your research? Choose BMC and benefit from:

- fast, convenient online submission

- thorough peer review by experienced researchers in your field

- rapid publication on acceptance

- support for research data, including large and complex data types

- gold Open Access which fosters wider collaboration and increased citations

- maximum visibility for your research: over $100 \mathrm{M}$ website views per year

At BMC, research is always in progress.

Learn more biomedcentral.com/submissions 